\title{
Better Outcomes or Better Access - which was better for mental health care?
}

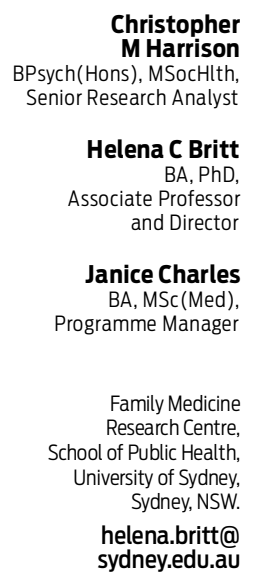

MJA 2012; 197: 170-172 doi: 10.5694/mjal2.10555

\author{
$\longrightarrow$
}

ince 2000, there has been a government focus on management of mental illness, particularly depression. In parallel with multiple National Mental Health Plans and funding of organisations which focus on depression, such as beyondblue, two major initiatives targeting mental health care in general practice have been introduced.

Recognising the importance of the general practitioner's role in managing mental health, the federal government introduced the Better Outcomes in Mental Health Care initiative in 2001. A new set of Medicare Benefits Schedule (MBS) items were created to allow GPs to claim for using focused psychological strategies and creating a threestep mental health care plan, which required at least two follow-up visits and a 1-6-month review. To access the incentive payments and refer patients, GPs had to complete training in psychoeducation, interpersonal therapy and cognitive behaviour therapy.

The three-step mental health component was withdrawn in 2007 as it was superseded by the GP Mental Health Care Plan - part of the Better Access to Psychiatrists, Psychologists and General Practitioners through the MBS initiative that was introduced in 2006. The most important changes were that GPs did not need additional training to conduct a GP Mental Health Care Plan and, unlike Better Outcomes, a review was not required to claim the incentive. The review became a separate item. Preparation of a GP Mental Health Care Plan allowed GPs to refer patients to psychologists for Medicare-subsidised care. The creation of a plan allowed trained GPs to provide patients with Medicare-subsidised care in their own practice.

Supporters of Better Outcomes have criticised Better Access since its inception. Criticisms include that Better Access is used more often by relatively advantaged patients from major cities; ${ }^{1}$ and, since GPs no longer have to review the plans, "GPs have allowed their role in Better Access to dwindle to that of glorified referrers". ${ }^{2}$

\begin{abstract}
Objective: To compare the Better Access to Psychiatrists, Psychologists and General Practitioners through the MBS initiative with the Better Outcomes in Mental Health Care initiative, to test contentions that Better Access is used more often by advantaged major city patients and that the role of GPs has been reduced to that of referrers.
\end{abstract}

Design and setting: Analysis of Bettering the Evaluation and Care of Health data relating to management of depression from April 1998 to March 2011, with the Better Outcomes period defined as January 2002 to October 2006 and the Better Access period defined as November 2006 to December 2011.

Main outcome measures: Rates of depression management by GPs, including rates of mental health care item claims, referrals, prescribing and counselling, by patient location and socioeconomic group.

Results: During the study period, rates of depression management increased and rates of referrals to psychiatrists halved. Compared with Better Outcomes, Better Access resulted in: increased depression management for advantaged major city and disadvantaged non-major city patients (16.0\% and $21.5 \%$ increases, respectively); a small decrease in prescribing for advantaged major city patients; decreases in GP counselling; increases in referrals to psychologists for all patient groups (three- to fourfold increases), with advantaged major city patients referred more often than patients in other groups; and increases in mental health care item claims for all patient groups (44-65-fold increases), with more claims for advantaged major city patients than both non-major city patient groups.

Conclusion: Far from becoming "glorified referrers", GPs remain heavily involved in the management of depression. Better Access brought about an enormous increase in access to primary care management of depression, although advantaged major city patients gained most. Any changes to the system must not compromise the strong improvements in access that have occurred for all groups.

Several evaluations of Better Access have been published over the past year. ${ }^{3,4}$ Critics have called for the use of Bettering the Evaluation and Care of Health (BEACH) data to assist the evaluation process. ${ }^{5}$ In this article, we test the above two contentions in GP management of depression, as depression is the most frequently managed psychological problem in general practice. ${ }^{6}$

\section{Methods}

We analysed data from the BEACH program (detailed methods are described elsewhere). ${ }^{7}$ In summary, each year about 1000 GPs from a national, rolling random sample (drawn by the Department of Health and Ageing) participate by providing patient and encounter information for 100 consecutive encounters with consenting, unidentified patients.

We weighted each April to March year in the dataset (about 100000 encounters) to match the age-sex dis- tribution of all GPs in the sample frame and for each GP's activity level (measured by number of MBS GP items claimed). The annual weighted BEACH encounter samples have repeatedly been shown to be representative of GP service items claimed through Medicare. ${ }^{7}$

The BEACH encounter data used in this study were: up to three MBS item numbers; postcode of patient's residential address; and up to four problems managed. GPs are instructed to describe the problem under management at the highest diagnostic level possible. For each problem, linked management data include medications, clinical treatments and referrals.

For each year between 1998 and 2011, we examined the rates of depression management by GPs, including rates of mental health care item claims, psychologist and psychiatrist referrals, prescribing and counselling.

We defined January 2002 to October 2006 as the Better Outcomes period and November 2006 to December 2011 as the Better Access 
ज $18 \square$ Depression contacts per 100 encounters

$\square$ Mental health care items per 100 depression contacts

¿ 16 - $\square$ Psychologist referrals per 100 depression contacts

ㄷ $\square$ Psychiatrist referrals per 100 depression contacts

पू山 $14-\square$ Total referrals per 100 depression contacts

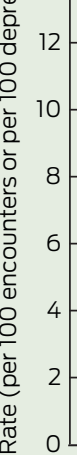

\author{
(1)
}

(1)

1

* The Better Outcomes initiative started in this data year. $\dagger$ The Better Access initiative started in this data year.

period. Applying the Socio-Economic Indexes for Areas ${ }^{8}$ to patients' residential postcodes, we defined Groups 6-10 as advantaged and Groups 1-5 as disadvantaged. Major city was defined according to the Australian Standard Geographical Classification. ${ }^{9}$ Depression was defined as problems classified as "P76 - Depressive disorder" in the International Classification of Primary Care (Version 2). ${ }^{10}$

We calculated robust $95 \%$ confidence intervals using survey procedures in SAS, version 9.2 (SAS
Institute Inc, Cary, NC, USA), which took into account the study's cluster design. Statistical significance of differences was judged by non-overlapping $95 \%$ confidence intervals.

The ethics committees of the University of Sydney and the Australian Institute of Health and Welfare approved the BEACH study and its further analysis.

\section{Results}

The overall rates of depression management, items claimed for depres- sion and referrals for depression are shown in Box 1. Rates of depression management increased significantly during the study period, with the sharpest increase between 2006-07 and 2008-09. Between 2002-03 and 2005-06 (Better Outcomes), GPs used about one mental health care item number per 500 depression contacts. Between 2007-08 and 2010-11 (Better Access), this changed to a mental health care item being claimed for about one in six depression contacts.

From the low point in 1999-00 to 2010-11, the rate of total referrals for

2 Comparison of rates of depression management by patient location and socioeconomic group during the Better Outcomes (January 2002 - October 2006) and Better Access (November 2006 - December 2011) initiatives

\begin{tabular}{|c|c|c|c|c|c|c|c|}
\hline & \multirow[b]{2}{*}{$\begin{array}{l}\text { Socioeconomic } \\
\text { group }\end{array}$} & \multicolumn{2}{|c|}{ Better Outcomes (rate $[95 \% \mathrm{Cl}]$ or number) } & \multicolumn{2}{|c|}{ Better Access (rate $[95 \% \mathrm{Cl}]$ or number) } & \multicolumn{2}{|c|}{ Significant change* } \\
\hline & & Major city & Non-major city & Major city & Non-major city & $\begin{array}{l}\text { Major } \\
\text { city }\end{array}$ & $\begin{array}{c}\text { Non- } \\
\text { major city }\end{array}$ \\
\hline \multirow{2}{*}{$\begin{array}{l}\text { Depression contacts per } 100 \\
\text { encounters }\end{array}$} & Advantaged & $3.76(3.63-3.89)$ & $4.40(4.14-4.65)$ & $4.36(4.23-4.49)$ & $4.75(4.51-5.00)$ & $+16.0 \%$ & - \\
\hline & Disadvantaged & $3.95(3.64-4.25)$ & $4.05(3.86-4.24)$ & $4.19(3.96-4.41)$ & $4.92(4.69-5.15)$ & - & $+21.5 \%$ \\
\hline \multirow{2}{*}{$\begin{array}{l}\text { Mental health care items } \\
\text { claimed per } 100 \text { depression } \\
\text { contacts }\end{array}$} & Advantaged & $0.28(0.15-0.42)$ & $0.34(0.05-0.62)$ & $18.18(17.08-19.28)$ & $15.07(13.32-16.82)$ & $\times 65$ & $\times 44$ \\
\hline & Disadvantaged & $0.27(0.05-0.49)$ & $0.30(0.05-0.55)$ & $15.58(13.58-17.57)$ & $13.76(12.04-15.48)$ & $\times 58$ & $\times 46$ \\
\hline \multirow{2}{*}{$\begin{array}{l}\text { Referrals to psychologists per } \\
100 \text { depression contacts }\end{array}$} & Advantaged & $2.78(2.41-3.16)$ & $3.15(2.41-3.89)$ & $11.65(10.95-12.35)$ & $9.79(8.58-11.01)$ & $\times 4.2$ & $\times 3.1$ \\
\hline & Disadvantaged & $1.87(1.22-2.52)$ & $2.74(2.03-3.46)$ & $8.36(7.18-9.53)$ & $8.65(7.67-9.63)$ & $\times 4.5$ & $\times 3.2$ \\
\hline \multirow{2}{*}{$\begin{array}{l}\text { Proportion of depression } \\
\text { contacts in which medication } \\
\text { was recorded }\end{array}$} & Advantaged & $65.80(64.44-67.16)$ & $68.23(65.88-70.57)$ & $62.33(61.08-63.58)$ & $64.69(62.36-67.02)$ & $-5.3 \%$ & - \\
\hline & Disadvantaged & $68.27(65.55-71.00)$ & $69.58(67.53-71.63)$ & $66.20(63.93-68.47)$ & $67.32(65.44-69.21)$ & - & - \\
\hline \multirow{2}{*}{$\begin{array}{l}\text { Proportion of depression } \\
\text { contacts involving GP } \\
\text { counselling }\end{array}$} & Advantaged & $43.82(42.25-45.39)$ & 41.31 (38.53-44.09) & $40.12(38.66-41.59)$ & $35.87(33.33-38.40)$ & $-8.4 \%$ & $-13.2 \%$ \\
\hline & Disadvantaged & $41.76(38.91-44.60)$ & $36.11(33.80-38.43)$ & 38.94 (36.32-41.57) & $31.80(29.58-34.02)$ & - & - \\
\hline \multirow{3}{*}{$\begin{array}{l}\text { Number of depression } \\
\text { contacts }^{\dagger}\end{array}$} & Advantaged & 9756 & 2842 & 12015 & 3053 & - & - \\
\hline & Disadvantaged & 2342 & 3478 & 2645 & 4129 & - & - \\
\hline & Total & 12098 & 6320 & 14660 & 7182 & - & - \\
\hline
\end{tabular}

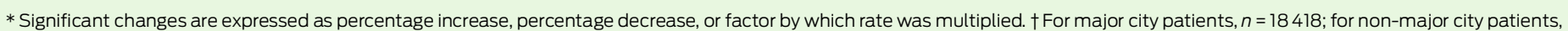
$n=21842$. 
depression management doubled, with the sharpest increase being after the introduction of the Better Access initiative. However, referrals to psychiatrists halved during the study period, while referrals to psychologists increased sixfold.

A comparison of depression management during the two initiatives by patient location and socioeconomic group is shown in Box 2. During Better Outcomes, the highest depression management rate was for advantaged patients from non-major city areas. The rate of depression management increased significantly during Better Access for advantaged patients from major cities (16.0\% increase) and for disadvantaged patients from nonmajor city areas (21.5\% increase).

During Better Outcomes, there were no significant differences between patient groups in the rate at which mental health care items were used. During Better Access, the use of these items increased significantly for all patient groups (44-65-fold increases), but were used at a significantly higher rate for major city advantaged patients than for both groups of non-major city patients.

During Better Outcomes, there was no significant difference between patient groups in referral rate to psychologists per 100 depression contacts. During Better Access, referrals to psychologists increased for all patient groups (three- to fourfold increases), but advantaged patients from major cities were referred significantly more often than patients in both disadvantaged groups.

During Better Access, the proportion of depression contacts with a record of medication being prescribed decreased significantly among the advantaged major-city patients while the proportion involving GP counselling decreased in both advantaged patient groups.

During Better Outcomes and Better Access, a greater proportion of disadvantaged patients from non-major city areas had a record of medication being prescribed at their depression contact than did advantaged patients from major cities. Conversely, in both periods a greater proportion of advantaged patients from major cities received GP counselling at their depression contact than did disadvantaged patients from non-major city areas.

\section{Discussion}

This study shows that, since the inception of Better Access, there has been a surge in referrals to psychologists for the management of depression. However, it also shows that GPs remained as active in the management of depression over the Better Access period as they were during Better Outcomes - GPs managed depression at a significantly higher rates, prescribed medication at similar rates, and provided counselling at slightly lower rates. We found no evidence from the $\mathrm{BEACH}$ data that the role of GPs has been reduced to that of "glorified referrers". ${ }^{2}$

Although relatively advantaged patients from major cities are more likely to have a mental health care item used and to be referred to a psychologist under the Better Access initiative, the difference is not as large as feared by some. The difference may be related to barriers of access to GPs and psychologists in rural areas and/ or a barrier of co-contribution for costs of most psychologist visits.

The study had some limitations. While we know the number of referrals written for psychologists, we do not know what proportion of these were used. Also, there may have been confounding influences over the study period for which adjustments cannot be made.

This study shows that GPs remain heavily involved in the management of depression. While Better Access has been used more by relatively advantaged patients from major cities, it also brought about an enormous increase among all patient groups in use of mental health care items and referrals to psychologists. Any changes to the system must not compromise the very large gains made for all groups in access to primary care management of depression.

Acknowledgements: We thank the GP participants in $\mathrm{BEACH}$ and all members of the BEACH team. During the data collection years reported here, the BEACH program was funded in all or some years by the Australian Government Department of Health and Ageing, the Australian Government Department of Veterans' Affairs, the Australian Institute of Health and Welfare, the National Prescribing Service, AstraZeneca, Roche, Janssen-Cilag, Merck Sharp and Dohme, Pfizer, SanofiAventis, Abbott, Wyeth, CSL Limited, GlaxoSmithKline, and the Office of the Australian Safety and Compensation Council (Australian Government Department of Employment and Workplace Relations).

Competing interests: No relevant disclosures. Received 28 Mar 2012, accepted 31 May 2012.

1 Crosbie D, Rosenberg S; COAG Mental Health Reform. Mental Health and the new Medicare Services: 2nd report November 2006 - August 2008. Canberra: Mental Health Council of Australia, 2008. http://www.mhca.org.au/ index.php/component/rsfiles/download? path=Mental\%20Health\%20Services/COAG\%2 OMBS\%202nd\%20Report\%20Sept\%202008. pdf\&ltemid=539 (accessed Jun 2012).

2 Rosenberg S, Hickie IB. Were the budgetary reforms to the Better Access to Mental Health Care initiative appropriate? No. Med J Aust 2011; 194: 595.

3 Pirkis J, Ftanou M, Williamson M, et al. Australia's Better Access initiative: an evaluation. Aust NZ J Psychiatry 2011; 45: 726-739.

4 Jorm AF. Australia's Better Access initiative: do the evaluation data support the critics? Aust NZJ Psychiatry 2011; 45: 700-704.

5 Rosenberg S, Hickie I. How to tackle a giant: creating a genuine evaluation of the Better Access Program. Australas Psychiatry 2010; 18: 496-502.

6 Harrison CM, Britt $\mathrm{H}$. The rates and management of psychological problems in Australian general practice. Aust N Z J Psychiatry 2004; 38: 781-788.

7 Britt H, Miller GC, Charles J, et al. General practice activity in Australia 2010-11. General practice series no. 29. Sydney: Sydney University Press, 2011. http://purl.library.usyd.edu.au/sup/ 9781920899868 (accessed Jun 2012).

8 Australian Bureau of Statistics. An introduction to Socio-Economic Indexes for Areas (SEIFA). Canberra: ABS, 2006. (ABS Cat. No. 2039.0.) http://www.ausstats.abs.gov.au/ausstats/ subscriber.nsf/0/ D729075E079F9FDECA2574170011B088/\$File/ 20390_2006.pdf (accessed Feb 2009).

9 Australian Bureau of Statistics. Australian standard geographical classification. Canberra: ABS, 2008. (ABS Cat. No. 1216.0.) http://www. abs.gov.au/AUSSTATS/abs@.nsf/DetailsPage/ 1216.0Jul\%202008?OpenDocument (accessed Dec 2008).

10 Classification Committee of the World Organization of Family Doctors. International Classification of Primary Care. 2nd ed. Oxford: Oxford University Press, 1998. 